\title{
PEMBERIAN TEKNIK VALSAVA MANUVER TERHADAP INTENSITAS NYERI PENUSUKAN ARTERIOVENOUS FISTULA (AVF) PASIEN HEMODIALISA
}

\section{VALSAVA MANUVER TECHNIQUES TO PAIN INTENSITY ARTERIOVENOUS FISTULA (AVF) PAIN IN HEMODIALIZED PATIENTS}

\author{
Mahruri Saputra ${ }^{\bowtie}$, Sabahul Badri \\ Prodi Sarjana Keperawatan, Universitas Bina Bangsa Getsempena, Jln. Tanggul Krueng Lamnyong No.34, Rukoh, \\ Kec. Syiah Kuala, Kota Banda Aceh. Indonesia \\ Correspondence Email : mahruri68@gmail.com
}

\begin{abstract}
ABSTRAK
Arteriovenous fistula (AVF) merupakan akses vaskuler eksternal sebagai tempat penusukan berulang pada pasien hemodialisa yang menyebabkan nyeri berulang. Pemberian teknik valsava manuver salah satu terapi nonfarmakologi yang dapat digunakan untuk menurunkan nyeri berulang penusukan AVF. Penelitian ini bertujuan mengidentifikasi pemberian teknik valsava manuver terhadap intensitas nyeri penusukan AVF pasien hemodialisa. Penelitian kuantitatif ini dengan desain quasi experiment pre and post one sampel test. Pengambilan sampel dengan teknik consecutive sampling pada 33 orang. Analisis data menggunakan paired t-test. Hasil menunjukkan sebelum dilakukan teknik valsava manuver skala nyeri penusukan AVF adalah 4,82 (SD=1,402) dan sesudah dilakukan teknik valsava manuver skala nyeri penusukan AVF adalah 3,45 (SD=1,301). Ada perbedaan skala nyeri penusukan AVF sebelum dan sesudah pemberian teknik valsava manuver pasien hemodialisa dengan $p$ value 0,000. Diharapkan pemberian teknik valsava manuver dapat menjadi intervensi mandiri keperawatan dalam menurunkan nyeri penusukan sehingga kenyamanan pasien hemodialis meningkat.
\end{abstract}

Kata kunci: arteriovenous fistula; hemodialisa; nyeri penusukan, valsava manuver.

\begin{abstract}
Arteriovenous fistula (AVF) is an external vascular access as a site for repeated punctures in hemodialysis patients which causes recurrent pain. The Valsalva maneuver is one of the non-pharmacological therapies that can be used to reduce repeated AVF stabbing pain. This study was purposed to identify the effectiveness of the Valsalva maneuver technique in reducing the intensity of AVF stabbing pain in hemodialysis patients. This quantitative research was a quasi-experimental pre and post one sample test design. Sampling technique used consecutive sampling technique on 33 people. Data analysis using paired t-test. The results showed that before the Valsalva maneuver the AVF stabbing pain scale was 4.82 $(S D=1.402)$ and after the Valsalva maneuver the AVF stabbing pain scale was $3.45(S D=1.301)$. There is a difference in the AVF stabbing pain scale before and after the Valsalva maneuver technique for hemodialysis patients with a $p$ value of 0.000. It is hoped that the Valsalva maneuver technique can be an independent nursing intervention in reducing stabbing pain so that the comfort of hemodialysis patients increases.
\end{abstract}

Keywords: Arteriovenous fistula, hemodialysis, stabbing pain, valsalva maneuver

Jurnal SMART Keperawatan is licensed under a Creative Commons Attribution-ShareAlike 4.0 International License. 


\section{PENDAHULUAN}

AVF merupakan pembedahan yang dilakukan (biasanya pada lengan bawah) dengan menggabungkan arteri dan vena besar yang menghasilkan fistula (Rosdahl \& Kowalski, 2012). Pasien yang menjalani hemodialisa akan merasakan efek dari penggunaan AVF yaitu nyeri saat penusukan pada area AVF (Kaza et al., 2014). Pasien akan mengalami stres dan nyeri akibat penusukan sekitar 300 kali dalam satu tahun (Çelik et al., 2011).

Hasil penelitian yang dilakukan (da Silva et al., 2016) di Brazil, menunjukkan bahwa dari 70 pasien yang menjalani kanulasi AVF, sebanyak $58,5 \%$ mengalami nyeri sedang, $20 \%$ mengalami nyeri berat, dan 11,5\% mengalami nyeri ringan. Menurut Bourbonnais dan Tousignant (2012) dalam penelitiannya menjelaskan bahwa dari 25 pasien yang di wawancara, sebanyak $12 \%$ pasien mengeluhkan nyeri pada saat insersi dan pencabutan jarum dengan tingkat nyeri ringan ke sedang.

Nyeri penusukan AVF merupakan keluhan tertinggi pasien yang menjalani hemodialisa (Figueiredo et al., 2008). Dampak lain penusukan AVF berulang yaitu adanya gangguan kondisi psikologi seperti rasa takut dan kecemasan (Alhani et al., 2010). Penelitian lain juga menunjukkan bahwa terdapat hubungan antara persepsi nyeri dengan kecemasan, depresi, gangguan tidur serta kualitas hidup dan angka kematian pada pasien hemodialisa (Harris et al., 2012).

Valsava manuver merupakan salah satu teknik non-faramkologi yang dapat dilakukan untuk menurunkan nyeri penusukan AVF (Sundaran et al., 2016). Valsava manuver yaitu suatu tindakan untuk melakukan ekspirasi secara paksa selama 16-20 detik dengan menutup glotis (mulut dan hidung) (Kumar et al., 2016). Hasil pengamatan yang dilakukan Mashhadi dan Loh (2011) menunjukkan bahwa banyak pasien yang menahan nyeri dengan menahan napas dan menutup glotis pada saat penusukan jarum yang dapat memicu terjadinya valsava manuver.

Penelitian yang dilakukan kepada 63 responden menunjukkan ada perbedaan nyeri penusukan AVF sebelum dan sesudah pemberian valsava manuver dengan selisih mean yaitu 1,35 $(S D=0,54), t=19,70, p=0,001$ (Saputra et al., 2018). Penelitian lain juga menunjukkan bahwa dari 182 sampel yang menerima penusukan vena, kelompok yang diberikan teknik valsava manuver secara signifikan menurunkan intensitas nyeri tusukan AVF $(p<0,001)$ jika dibandingkan dengan kelompok kontrol. Valsava manuver yang dilakukan selama 16-20 detik saat penusukan vena dapat mengurangi insiden dan keparahan nyeri saat penusukan vena (Suren et al., 2013).

Saraf sensorik dari berbagai organ seperti orofaring, saluran pencernaan bagian atas, perut dan rongga dada mengirimkan informasi sepanjang vagus menuju traktus solitarius. Saraf vagus juga membawa serat nosisepsis sepanjang jalur ini. Valsava manuver meningkatkan tekanan intra thorak dan menyebabkan aktivasi baroreseptor, yang merangsang stimulasi saraf vagus. Akibatnya, stimulasi saraf vagus menginduksi efek antinosiseptif (Liporace et al., 2001).

Berdasarkan studi pendahuluan yang dilakukan pada 14 September 2020 di RSUD Zubir Mahmud didapatkan hasil bahwa seluruh pasien yang menjalani hemodialisa belum pernah diberikan terapi apapun untuk mengurangi nyeri saat dilakukan penusukan AVF. Penelitian ini dilakukan untuk mengidentifikasi pemberian teknik valsava manuver terhadap intensitas nyeri penusukan AVF pasien hemodialisa.

\section{METODE}

Penelitian ini merupakan penelitian quantitative design dengan pendekatan desain quasi eksperimen pre and post one sampel test dalam bentuk time series. Populasi yang digunakan adalah seluruh pasien hemodialisa yang menggunakan akses vaskuler AVF di ruang hemodialisa RSUD Zubir Mahmud. Jumlah sampel penelitian ini diambil dari hasil penelitian sebelumnya yang dihitung berdasarkan tabel power analisis. Jumlah sampel yang didapatkan dari power 0,8, effect size 0,7 , dan $\alpha=0,05$ adalah 33 responden. Metode dalam pengambilan sampel yang digunakan adalah consecutive sampling dimana pemilihan sampel dilakukan dengan 
memilih semua individu yang ditemui dan memenuhi kriteria sampai jumlah sampel yang dibutuhkan terpenuhi (Dharma, 2015).

Instrumen penelitian ini menggunakan Numerical Pain Rating Scale (NPRS) dan lembar pencatatan tingkat nyeri. Teknik pengumpulan data dilakukan dalam dua kali pertemuan pada pasien yang rutin melakukan hemodialisa dua kali seminggu. Pada pertemuan pertama, responden dinilai tingkat nyerinya saja setelah dilakukan penusukan AVF dan pada pertemuan kedua responden yang sama diberikan valsava manuver dengan meminta responden menutup mulut dan hidung serapat-rapatnya menggunakan tangan kemudian responden dianjurkan melakukan hembusan napas dengan sekuat tenaga selama 16-20 detik dan saat bersamaan penusukan AV fistula dilakukan. Kemudian, setelah selasai penusukan peneliti mengukur intensitas nyeri responden.

Sampel penelitian yang diambil adalah responden yang menjalani hemodialisa rutin dan memenuhi kriteria inklusi yaitu pasien menjalani hemodialisa rutin 2 kali seminggu di RSUD Zubir Mahmud, tidak merasa sakit pada area tubuh yang lain sebelum penusukan jarum fistula, tidak memiliki riwayat menggunakan obat-obatan, penusukan AVF bisa dilakukan setiap hemodialisa, tidak adanya peradangan, kerusakan, kemerahan dan memar di kulit dimana jarum dimasukkan ke fistula, tidak memiliki riwayat penyakit jantung, galukoma, peningkatan tekanan di otak, dan tidak baru menjalani operasi mata. Sedangkan kriteria eksklusi dalam penelitian ini adalah dengan alasan sepihak menghentikan keikutsertaan dalam penelitian, meninggal atau tidak melanjutkan perawatan pada pertemuan kedua, mengkonsumsi obat penenang sebelum memulai hemodialisa.

Analisis univariat dilakukan menggunakan analisis deskriptif melalui distribusi frekuensi dan persentase data yang meliputi umur, jenis kelamin, lama menjalani hemodialisa dan lama terpasang AV fistula, serta data intensitas nyeri pasien pada pertemuan pertama sebelum pemberian teknik valsava manuver (pretest) dan pertemuan kedua setelah pemberian teknik valsava manuver (posttest). Penelitian ini dinyatakan layak dilakukan berdasarkan surat yang di keluarkan oleh Lembaga Penelitian dan pengabdian Masayarakat (LPPM) Universitas Bina Bangsa Getsempena dengan Nomor: 043/131013.03/PPM/2021.

\section{HASIL}

\section{Karakterisitk Responden}

Berdasarkan tabel 1. Kelompok usia responden penelitian ini dikategorikan menurut Depkes RI (2009). Penelitian ini menemukan bahwa sebanyak $36,4 \%$ responden berusia antara 56 65 tahun (lansia awal) dan sebanyak 60,6\% responden berjenis kelamin laki-laki. Hasil penelitian ini juga menunjukkan sebanyak $54,5 \%$ responden menjalani HD selama 3-28 bulan dan Sebanyak $60,6 \%$ responden telah terpasang AVF 2-23 bulan dengan rata-rata lama terpasang AVF yaitu $24(S D=18,83)$.

Tabel 1 Distrubusi frekuensi dan persentase berdasarkan karakteristik responden di ruang Hemodialisa RSUD Zubir Mahmud

\begin{tabular}{|c|c|c|c|}
\hline No & $\begin{array}{l}\text { Karakteristik } \\
\text { Responden }\end{array}$ & $f$ & $\%$ \\
\hline \multirow{8}{*}{1} & Usia (Tahun) & & \\
\hline & 17-25 Tahun & 2 & 6,1 \\
\hline & 26-35 Tahun & 4 & 12,1 \\
\hline & 36-45 Tahun & 5 & 15,2 \\
\hline & 46-55 Tahun & 5 & 15,2 \\
\hline & 56-65 Tahun & 12 & 36,4 \\
\hline & $>65$ Tahun & 5 & 15,2 \\
\hline & Mean $\pm S D$ & \multicolumn{2}{|c|}{$50,61 \pm 14,115$} \\
\hline \multirow[t]{3}{*}{2} & Jenis Kelamin & & \\
\hline & Perempuan & $\begin{array}{l}13 \\
20\end{array}$ & $\begin{array}{l}39,4 \\
606\end{array}$ \\
\hline & Laki-laki & & \\
\hline \multirow[t]{5}{*}{3} & $\begin{array}{l}\text { Lama Menjalani HD } \\
\text { (Bulan) }\end{array}$ & & \\
\hline & $3-28$ & 18 & 54,5 \\
\hline & $29-54$ & 11 & 33,3 \\
\hline & $55-78$ & 4 & 12,2 \\
\hline & Mean $\pm S D$ & \multicolumn{2}{|c|}{$23,52 \pm 17,9$} \\
\hline \multirow[t]{5}{*}{4} & $\begin{array}{l}\text { Lama Terpasang AVF } \\
\text { (Bulan) }\end{array}$ & & \\
\hline & $2-23$ & 20 & 60,6 \\
\hline & $24-47$ & 10 & 30,3 \\
\hline & $48-66$ & 3 & 9,1 \\
\hline & Mean $\pm S D$ & \multicolumn{2}{|c|}{$24 \pm 18,830$} \\
\hline
\end{tabular}


Intensitas nyeri penusukan AVF sebelum dan sesudah Pemberian Teknik Valsava Manuver

Berdasarkan tabel 2. menunjukkan bahwa sebelum dilakukan pemberian teknik valsava manuver, sebanyak $69,7 \%$ responden mengalami nyeri penusukan AVF dengan intensitas 4-6 (sedang) dan rata-rata nyeri 4,82 $(S D=1,402)$. Sedangkan, sesudah pemberian teknik valsava manuver, sebanyak $57,6 \%$ responden mengalami nyeri penusukan AVF dengan intensitas 1-3 (ringan) dan rata-rata nyeri 3,45 $(S D=1,301)$.

Tabel 2 Distribusi frekuensi berdasarkan intensitas nyeri penusukan AVF sebelum dan sesudah pemberian teknik valsava manuver di ruang hemodialisa RSUD Zubir Mahmud

\begin{tabular}{|c|c|c|c|c|c|}
\hline \multirow{3}{*}{ No } & \multirow{3}{*}{$\begin{array}{l}\text { Intensitas } \\
\text { Nyeri }\end{array}$} & \multicolumn{4}{|c|}{ Valsava Manuver } \\
\hline & & \multicolumn{2}{|c|}{ Sebelum } & \multicolumn{2}{|c|}{ Sesudah } \\
\hline & & $F$ & $\%$ & $f$ & $\%$ \\
\hline 1 & 1-3 (Ringan) & 6 & 18,2 & 19 & 57,6 \\
\hline 2 & 4-6 (Sedang) & 23 & 69,7 & 14 & 42,4 \\
\hline 3 & 7-10 (Berat) & 4 & 12,1 & 0 & 0 \\
\hline \multicolumn{2}{|r|}{ Mean $\pm S D$} & \multicolumn{2}{|c|}{$4,82 \pm 1,402$} & \multicolumn{2}{|c|}{$\begin{array}{c}3,45 \pm 1,30 \\
1\end{array}$} \\
\hline & Min-Max & \multicolumn{2}{|c|}{$3-8$} & \multicolumn{2}{|c|}{$2-6$} \\
\hline
\end{tabular}

Uji normalitas data yang digunakan pada penelitian ini adalah skewness dan kurtosis. Kriteria distribusi data normal jika nilai rasio skewness dan kurtosis diantara rentang $-2 \mathrm{~s} / \mathrm{d}$ 2 (Dahlan, 2011).

Uji normalitas penelitian ini didapatkan nilai rasio skewness/standart error skewness 0,48 dan nilai rasio kurtosis/standart error kurtosis 0,78 dan setelah dilakukan valsavar manuver didapatkan nilai rasio skewness/standart error skewness 1,6 dan nilai rasio kurtosis/standart error kurtosis $-0,50$ yang artinya data berdistribusi normal.

Perbedaan Intensitas Nyeri penusukan AVF sebelum dan sesudah Pemberian Teknik Valsava Manuver

Berdasarkan Tabel 3. menunjukkan bahwa terdapat perbedaan antara intensitas nyeri penusukan AVF sebelum dan sesudah dilakukan valsava manuver dengan rata-rata penurunan yaitu 1,364 .
Tabel 3 Hasil analisis uji paired t-test perbedaan rata-rata intensitas nyeri penusukan AVF sebelum dan sesudah Pemberian Teknik Valsava Manuver di ruang Hemodialisa RSUD Zubir Mahmud

\begin{tabular}{lcccc}
\hline & $\begin{array}{c}\text { Selisih } \\
\text { Nilai } \\
\text { Mean }\end{array}$ & SD & $\boldsymbol{t}$ & $\boldsymbol{p}$ \\
\hline $\begin{array}{l}\text { Sebelum- } \\
\begin{array}{l}\text { Sesudah } \\
\text { dilakukan }\end{array}\end{array}$ & 1,364 & 0,549 & 14,275 & 0,000 \\
$\begin{array}{l}\text { valsava } \\
\text { manuver }\end{array}$ & & & & \\
\hline
\end{tabular}

Hasil uji analisis statistik juga menunjukkan bahwa intensitas nyeri penusukan AVF setelah dilakukan dilakukan valsava manuver diperoleh nilai $p=0,000$ dengan tingkat kepercayaan 95\%. Maka, dapat disimpulkan bahwa nilai $p<0,05$, yang artinya terdapat perbedaan intensitas nyeri penusukan AVF sebelum dan sesudah dilakukan valsava manuver pada pasien hemodialisa di RSUD Zubir Mahmud.

\section{PEMBAHASAN}

Intensitas nyeri penusukan AVF sebelum Pemberian Teknik Valsava Manuver

Hasil penelitian ini menunjukkan bahwa, dari 33 responden sebelum diberikan valsava manuver saat penusukan AVF pada pasien hemodialisa didapatkan bahwa sebanyak $69,7 \%$ responden mengalami nyeri penusukan AVF dengan intensitas 4-6 (sedang) dan rata-rata nyeri 4,82 $(S D=1,402)$.

Penelitian da Silva et al., (2016) menunjukkan dari 70 responden, sebanyak $58,5 \%$ responden mengalami nyeri sedang pada saat penusukan AVF. Hasil penelitian ini juga sejalan dengan penelitian Kaza et al., (2014) yang menunjukkan dari 56 responden yang mengalami nyeri penusukan AVF sebanyak $62 \%$ responden mengalami nyeri sedang. Penelitian Çelik et al., (2011) juga menunjukkan bahwa dari 41 responden sebanyak 48,8\% responden pada kelompok tanpa intervensi mengalami nyeri sedang.

Arab et al., (2017) dalam penelitiannya juga menunjukkan nyeri penusukan AVF sebelum penusukan dalam kategori sedang dengan rata-rata nyeri $5,40 \quad(S D=1,75)$. 
Penelitian Golda et al., (2016) juga menunjukkan hasil yang sama dimana nyeri penusukan AVF sebelum intervensi dalam rentang yaitu sedang dengan rata-rata nyeri 6,3 $(S D=1,15)$.

Intensitas nyeri penusukan AVF dapat berkaitan dengan faktor usia, dimana lebih dari sepertiga responden $(36,4 \%)$ berusia antara 56-65 (lansia awal) dengan rata-rata usia responden 50,61 tahun. Hasil penelitian Sanusi (2015) menunjukkan sebanyak $87 \%$ responden yang mengalami nyeri sedang berusia kurang dari 65 tahun. Helms dan Barone (2009) menyatakan bahwa pada usia lanjut, serabut $\mathrm{C}$ lebih sering bekerja dibandingkan dengan serabut A-delta. Selain itu, kemampuan komunikasi, kognitif dan kerusakan reflex juga dapat menjadi penyebab perlambatan peyampaian rasa nyeri pada lansia.

Selanjutnya, hasil penelitian menunjukkan bahwa sebanyak 60,6\% responden berjenis kelamin laki-laki. Hasil penelitian Aitken et al., (2013) menunjukkan tidak ada hubungan yang signifikan antara nyeri penusukan AVF dengan jenis kelamin. Sedangkan hasil penelitian Sabitha et al., (2008) mendapatkan hasil nyeri penusukan AVF lebih dirasakan pada wanita. Menurut Palmeira et al., (2011) wanita cenderung memiliki ambang nyeri yang lebih rendah dibandingkan dengan pria, karena rasa sakit dipengaruhi oleh mekanisme yang dapat merangsang atau menghambat sensasi nyeri. Mekanisme potensial yang dapat mempengaruhi nyeri yaitu hormon, perbedaan otak dan sumsum tulang belakang antara pria dan wanita, genetik, peran sosial budaya, stres, dan agen-agen neuroaktif (Helms \& Barone, 2009).

Berdasarkan hasil uraian diatas, ratarata intensitas nyeri penusukan AVF sebelum dilakukan intervensi yang dialami pasien hemodialisa dalam kategori sedang. Sementara, karakteristik umur pasien dapat mempengaruhi intensitas nyeri penusukan AVF yang dirasakan oleh pasien. Sedangkan jenis kelamin tidak berkaitan secara langsung terhadap intensitas nyeri penusukan AVF yang dirasakan pasien hemodialisa.

\section{Intensitas nyeri penusukan AVF sesudah Pemberian Teknik Valsava Manuver}

Berdasarkan hasil penelitian, dari 33 pasien yang dilakukan pemberian teknik valsava manuver, sebanyak $57,6 \%$ responden mengalami nyeri penusukan AVF dengan intensitas 1-3 (ringan) dan rata-rata nyeri 3,45 $(S D=1,301)$. Hasil penelitian yang dilakukan oleh Agarwal et al., (2005) dari 25 responden pada masing-masing kelompok yaitu kelompok kontrol, valsava manuver, dan bola didapatkan hasil bahwa pada kelompok valsava manuver kurang dari tiga per empat (72\%) pasien mengalami nyeri ringan, lebih baik dibandingkan dengan kelompok kontrol (44\%) dan kelompok bola (36\%). Hasil penelitian Saputra et al., (2020) juga menunjukkan setelah pemberian teknik valsava manuver, lebih dari setengah (55,6\%) responden mengalami nyeri penusukan AV fistula dengan intensitas 1-3 (ringan).

Valsava manuver yaitu melakukan ekspirasi selama 16-20 detik secara paksa dengan menutup glottis (mulut dan hidung) (Engstrom \& Martin, 2001; Kumar et al., 2016). Valsava manuver dapat merangsang saraf vagus melalui aktivasi lengkung baroreseptor kardiopulmonal (Bennett et al., 1976). Ditinjau dari hasil penelitian yang dilakukan Randich \& Maixner (1984) tentang farmakologi, neuroanatomi, elektrofisiologi, dan perilaku menunjukkan system yang mengendalikan fungsi kardiovaskuler berhubungan erat dengan system yang memodulasi persepsi nyeri. Lebih lanjut, Randich dan Maixner menyatakan bahwa aktivasi lengkung reflek baroreseptor kardiopulmonal atau lengkung baroreseptor sinaortik dapat menginduksi antinosisepsi.

Penurunan nyeri penusukan AV fistula pada pasien hemodialisa dapat dikaitkan dengan aktivasi lengkung reflek baroreseptor kardiopulmonal atau lengkung baroreseptor sinaortik yang disebabkan oleh valsava manuver. Dimana aktivasi baroreseptor dapat menstimulasi saraf vagus. Kemudian, impuls 
yang dihantarkan ke nukleus traktus solitarius. Traktus solitarius merupakan tempat pertemuan antara masukan aferen sistem saraf vagus dan lamina tulang belakang yang terkait dengan jalur nosiseptif (Bruehl \& Chung, 2004). Dengan melakukan valsava manuver diharapkan impuls yang terlebih dahulu diterima nukleus traktus solitarius berasal dari impuls yang tranmisi oleh saraf vagus. Artinya pada saat bersamaan rangsangan nyeri akibat penusukan AV fistula tidak dapat ditransmisi keotak untuk dipersepsikan. Proses ini sesuai dengan teori gate control yang dikemukakan oleh Melzack dan Wall (1965) dimana hanya satu rangsangan yang dapat diterima oleh otak untuk dipersepsikan. Jika salah satu rangsangan sudah melewati gerbang dan masuk kedalam system saraf otak maka rangsangan yang lainnya akan terblok dan tidak akan dirasakan.

Hasil uji statistik terhadap nyeri penusukan AV fistula didapatkan bahwa, nyeri penusukan AV fistula setelah pemberian teknik valsava manuver berada pada intensitas ringan dengan nilai rata-rata $3,52 \quad(S D=1,29)$. Penelitian yang dilakukan Sundaran et al., (2016) juga menyatakan bahwa intensitas nyeri kanulasi vena yang dialami responden pada kelompok valsava manuver yaitu ringan dengan nilai rata-rata 1,53 $(S D=0,63)$.

Berdasarkan uraian diatas, setelah pemberian teknik valsava manuver terjadi penurunan intensitas nyeri penusukan AV fistula pada pasien hemodialisa. Sementara itu, karena teknik valsava manuver ini sangat mudah dilakukan sehingga pasien dapat dengan tepat untuk melakukannya dan juga berdampak langsung pada penurunan intensitas nyeri penusukan $\mathrm{AV}$ fistula.

\section{Perbedaan intensitas nyeri penusukan AVF sebelum dan setelah pemberian Teknik Valsava Manuver}

Berdasarkan hasil penelitian didapatkan bahwa ada perbedaan antara intensitas nyeri penusukan AVF sebelum dan sesudah dilakukan valsava manuver dengan rata-rata penurunan yaitu 1,364. Berdasarkan hasil uji statistik didapatkan nilai $t_{\text {hitung }}=14,275$ dan nilai $p=0,000$. Artinya, ada antara intensitas nyeri penusukan AVF sebelum dan sesudah dilakukan valsava manuver. Dimana, dengan pemberian teknik valsava manuver dapat menurunkan nyeri penusukan AVF pada pasien hemodialisa.

Hasil penelitian ini didukung oleh penelitian yang dilakukan oleh Saputra et al., (2020) yang menunjukkan bahwa ada perbedaan signifikan antara sebelum dan sesudah pemberian teknik valsava manuver dengan selisih mean yaitu $1,35(S D=0,54)$, $p=0,000$.

Hasil penelitian ini didukung oleh penelitian yang dilakukan oleh Davtalab et al., (2016) yang menyatakan terdapat perbedaan signifikan antara intensitas nyeri penusukan sebelum dan sesudah pemberian valsava manuver $(p=0,001)$. Penelitian yang dilakukan Agarwal et al., (2005) juga menyatakan bahwa terdapat penurunan intensitas nyeri yang signifikan saat kanulasi intravena pada pemberian teknik valsava manuver dengan nilai $p=0,001$.

Penelitian yang dilakukan oleh Sundaran et al., (2016) juga menemukan hasil yang sama dimana efek pemberian valsasava manuver dapat menurunkan nyeri kanulasi intravena dengan nilai $t=-2,053$ dan nilai $p=0,045$. Suren et al., (2013) juga menyatakan terdapat perbedaan intensitas nyeri yang signifikan pada kelompok valsava dibandingkan dengan kontrol grup $(p<0,05)$.

Menurut Usichenko et al., (2004) valsava manuver dapat mengaktivasi baroreseptor dan menginduksi nosisepsis. Valsava manuver dapat meningkatkan tekanan intratorak dengan cara menghembuskan napas dan menutup hidung sehingga menutup glotis selama periode waktu tertentu (Mashhadi \& Loh, 2011). Lebih lanjut, Mashhadi dan Loh menyatakan hal tersebut dapat menyebabkan peningkatan aliran darah yang mengakibatkan penurunan darah yang masuk ke thorak dan mengaktifkan baroreseptor.

Menurut Bruehl dan Chung (2004) aktivasi baroreseptor dapat merangsang stimulasi saraf vagus. Kemudian, saraf vagus menghantarkan impuls ke nukleus traktus solitarius. Nukleus traktus solitarius merupakan interface antara sistem otonom dan sensorik, 
dan merupakan lokasi sinaps pertama pada jalur refleks baroreseptor. Nukleus traktus solitarius merupakan penerima masukan aferan dari saraf vagus dan lamina tulang belakang yang terkait dengan proses nosiseptif.

Lebih lanjut, Bruehl dan Chung menyatakan stimulasi nukleus traktus solitarius dalam jalur pengaturan nyeri dapat menginduksi antinosiseptif. Antinosiseptif yang dirangsang oleh nukleus traktus solitarius dapat berasal dari proyeksi eferen langsung dan tidak langsung ke periaqueductal gray (PAG) dan struktur otak lainnya seperti nucleus raphe magnus (NRM) dan rostral ventrolateral medulla (RVM) yang diketahui terlibat dalam modulasi jalur nyeri. Selain daerah otak atas, proyeksi dari nukleus traktus solitarius menuju lokus koeruleus medula mungkin juga merupakan kontributor penting antinosisepsi terkait dengan tekanan darah, mengingat stimulasi langsung daerah ini menimbulkan analgesia. Interkoneksi antara nukleus traktus solitarius dan lokus koeruleus sangat penting dalam memediasi analgesia nonopioid, mengingat lokus koeruleus adalah sumber utama neuron noradrenergik di neuraksis.

Hasil penelitian ini membuktikan bahwa pemberian teknik valsava manuver dapat menurunkan intensitas nyeri penusukan AV fistula pada pasien yang menjalani hemodialisa.

\section{KESIMPULAN}

Ada perbedaan intensitas nyeri penusukan AVF sebelum dan sesudah pemberian teknik valsava manuver pada pasien hemodialisa di RSUD Zubir Mahmud. Diharapkan teknik valsava manuver bisa menjadi kompetitor rangsangan nyeri (nosisepttif) saat penusukan AVF. Perawat mampu menerapkan intervensi pemberian teknik valsava manuver menjadi salah satu intervensi mandiri untuk meningkatkan kenyamanan pasien dan mengurangi nyeri penusukan sehingga bisa berdampak terhadap penurunan kecemasan yang dirasakan akibat dari penusukan AVF yang berulang. Diharapkan kepada pihak RSUD Zubir Mahmud untuk membuat intervensi pemberian teknik valsava manuver menjadi SOP dalam menurunkan nyeri penusukan AVF di ruang hemodialisa.

\section{REFERENSI}

Agarwal, A., Sinha, P. K., Tandon, M., Dhiraaj, S., \& Singh, U. (2005). Evaluating the efficacy of the Valsalva maneuver on venous cannulation pain: A prospective, randomized study. Anesthesia and Analgesia, 101(4), 1230-1232.

https://doi.org/10.1213/01.ane.0000167270.1 5047.49

Aitken, E., McLellan, A., Glen, J., Serpell, M., Mactier, R. I, \& Clancy, M. (2013). Pain resulting from arteriovenous fistulae: prevalence and impact. Clinical Nephrology, 80(Vovember), 328-333. https://doi.org/10.5414/CN107917

Alhani, F., Shad, H., Anoosheh, M., \& Hajizadeh, E. (2010). The effect of programmed distraction on the pain caused by venipuncture among adolescents on hemodialysis. Pain Management Nursing, 11(2), 85-91. https://doi.org/10.1016/j.pmn.2009.03.005

Arab, V., Bagheri-Nesami, M., Mousavinasab, S. N., Espahbodi, F., \& Pouresmail, Z. (2017). Comparison of the Effects of Hegu Point Ice Massage and 2\% Lidocaine Gel on Arteriovenous Fistula Puncture-Related Pain in Hemodialysis Patients: A Randomized Controlled Trial. Journal of Caring Sciences, 6(2), 141-151. https://doi.org/10.15171/jcs.2017.014

Bennett, T., Hosking, D. J., \& Hampton, J. R. (1976). Baroreflex sensitivity and responses to the Valsalva manoeuvre in subjects with diabetes mellitus. Jorunal of Neurology, Neurosergury and Psychiatri, 39, 178-183.

Bourbonnais, F. F., \& Tousignant, K. F. (2012). The Pain Experience of Patients On Maintenance Hemodialysis. Nephrology Nursing Journal, 39(1), 13-20.

Bruehl, S., \& Chung, O. Y. (2004). Interactions between the cardiovascular and pain regulatory systems: An updated review of mechanisms and possible alterations in chronic pain. Neuroscience and Biobehavioral 
Reviews, 28(4), 395-414. https://doi.org/10.1016/j.neubiorev.2004.06.0 04

Çelik, G., Özbek, O., Yılmaz, M., Duman, l., Özbek, S., \& Apiliogullari, S. (2011). Vapocoolant Spray vs Lidocaine / Prilocaine Cream for Reducing the Pain of Venipuncture in Hemodialysis Patients:: A Randomized, Placebo-Controlled, Crossover Study. International Journal of Medical Sciences, $8(7), 623-627$.

da Silva, O. M., Rigon, E., Corradi Dalazen, J. V., Bissoloti, A., \& Rabelo-Silva, E. R. (2016). Pain during Arteriovenous Fistula Cannulation in Chronic Renal Patients on Hemodialysis. Open Journal of Nursing, 06(12), 1028-1037. https://doi.org/10.4236/ojn.2016.612098

Dahlan, M. S. (2011). Statistik untuk kedokteran dan kesehatan (5th ed.). Salemba Medika.

Davtalab, E., Naji, S., \& Shahidi, S. (2016). Comparing the effects of Valsalva maneuver and ice massage at Hoku point methods on pain intensity within the needle insertion to the arteriovenous fistula ( AVF ) for patients undergoing hemodialysis in the selected hospitals in Isfahan in 2015. International Journal of Medical Research \& Health Sciences, 5(5), 101-107.

Dharma, K. K. (2015). Metodologi Penelitian Keperawatan: Panduan Melaksanakan dan Menerapkan Hasil Penelitian. Trans Info Media.

https://doi.org/10.1017/S175173110800373X. 259

Engstrom, J. W., \& Martin, J. B. (2001). Disorders of the autonomic nervous system. In: Principals of internal medicine (F. Braunwald E (ed.); Braunwald). McGraw-Hill.

Figueiredo, A. E., Viegas, A., Monteiro, M., \& PoliDe-Figueiredo, C. E. (2008). Research into pain perception with arteriovenous fistula (AVF) cannulation. Journal of Renal Care, 34(4), 169-172. https://doi.org/10.1111/j.17556686.2008.00041.x

Golda, M., Revathi, D., Subhashini, N., Mathew, J.,
\& Indira, A. (2016). Assess the effectiveness of cold application on pre procedure ( AV fistula puncture ) pain among hemodialysis patients in tertiary care hospital, Nellore. International Journal of Applied Research, 2(6), 660-664.

Harris, T. J., Nazir, R., Khetpal, P., Peterson, R. A., Chava, P., Patel, S. S., \& Kimmel, P. L. (2012). Pain, sleep disturbance and survival in hemodialysis patients. Nephrology Dialysis Transplantation, 27(2), 758-765. https://doi.org/10.1093/ndt/gfr355

Helms, J., \& Barone, C. (2009). Physiology and Treatment of Pain. Critical Care Nurse, 28, 38-49; quiz 50. https://doi.org/10.4037/ccn2008.28.6.38

Kaza, B. N. K., Sabi, K. A., Amekoudi, E. Y. M., Imangue, G., Badibanga, J., Tsevi, C. M., Wendkuuni, A. Y. B., Teuwafeu, D. G., Benghanem, M. G., \& Ramdani, B. (2014). Pain during Arterio-Venous Fistula (AVF) Cannulation. American Journal of Internal Medicine, 2(5), 87-89. https://doi.org/10.11648/j.ajim.20140205.12

Kumar, S., Gautam, S. K. S., Gupta, D., Agarwal, A., Dhirraj, S., \& Khuba, S. (2016). The effect of valsalva maneuver in attenuating skin puncture pain during spinal anesthesia: A randomized controlled trial. Korean Journal of Anesthesiology, 69(1), 27-31. https://doi.org/10.4097/kjae.2016.69.1.27

Liporace, J., Hucko, D., Morrow, R., Barolat, G., Nei, M., Schnur, J., \& Sperling, M. (2001). Vagal nerve stimulation: adjustments to reduce painful side effects. Neurology, 57(5), 885-886.

https://doi.org/10.1212/WNL.57.5.885

Mashhadi, S. A., \& Loh, C. Y. Y. (2011). Valsalva manoeuvre and the wrist block. European Journal of Plastic Surgery, 34(5), 421-422. https://doi.org/10.1007/s00238-011-0567-0

Melzack, R., \& Wall, P. (1965). Pain Mechanism: A new Theory. In Science (Vol. 150, pp. 971979).

https://doi.org/10.1126/science.150.3699.971

Palmeira, C. C. de A., Ashmawi, H. A., \& Posso, I. de P. (2011). Sex and Pain Perception and Analgesia. Revista Brasileira de 
Anestesiologia, 61(6), 814-828. https://doi.org/10.1016/S0034-

7094(11)70091-5

Randich, A., \& Maixner, W. (1984). Interactions between cardiovascular and pain regulatory systems. Neurosci Biobehav Rev ., 8(3), 343367. https://doi.org/10.1016/01497634(84)90057-5.

Rosdahl, C. B., \& Kowalski, M. T. (2012). Textbook of Basic Nursing (10th ed.). Lippincott Williams \& Wilkins.

Sabitha, P. B., Khakha, D. C., Mahajan, S., Gupta, S., Agarwal, M., \& Yadav, S. L. (2008). Effect of cryotherapy on arteriovenous fistula puncture-related pain in hemodialysis patients. Indian Journal of Nephrology, 18(4), 155-158 4p. https://doi.org/10.4103/09714065.45290

Saputra, M., Harahap, I. A., \& Kasiman, S. (2018). Pengaruh pemberian tekn ik valsava manuver, teknik kompres dingin kontralateral. Universitas Sumatera Utara.

Saputra, M., Harahap, I. A., \& Kasiman, S. (2020). Valsalva Maneuver to Decrease Pain Intensity During Arteriovenous Fistula Insertion in Hemodialysis Patients. Jurnal Keperawatan Indonesia, 23(2), 136-144. https://doi.org/10.7454/jki.v23i2.645
Sundaran, J. P., Khan, F., Bansal, P., \& Jyotsana. (2016). An Experimental Study to Assess the Effectiveness of Valsalva Maneuver Prior to Intravenous Cannulation on Pain Perception among ... An Experimental Study to Assess the Effectiveness of Valsalva Maneuver Prior to Intravenous Cannulation on Pain Perception. Research \& Reviews: Journal of Surgery, 5(2), 1-6.

Suren, M., Kaya, Z., Ozkan, F., Erkorkmaz, U., Arici, S., \& Karaman, S. (2013). Comparison of the use of the Valsalva maneuver and the eutectic mixture of local anesthetics (EMLA $®$ ) to relieve venipuncture pain: $A$ randomized controlled trial. Journal of Anesthesia, 27(3), 407-411. https://doi.org/10.1007/s00540-0121540-1

Usichenko, T. I., Pavlovic, D., Foellner, S., \& Wendt, M. (2004). Reducing venipuncture pain by a cough trick: a randomized crossover volunteer study. Anesthesia and Analgesia, 98(2), 343-345, table of contents. https://doi.org/10.1213/01.ANE.0000094983.1 6741.AF 